\title{
A new era of Esophagus: indexed to MEDLINE and obtained IF over 2
}

\author{
Soji Ozawa ${ }^{1}$
}

Received: 7 January 2020 / Published online: 11 January 2020

(c) The Japan Esophageal Society 2020

Esophagus, the official journal of the Japan Esophageal Society, was first published in December 2003. In the inaugural issue, Masayuki Imamura, Consulting Editor of Esophagus at the time, said "We believe that this journal will contribute to the promotion of international communication among scientists concerned with diseases of the esophagus and related organs, as we publish articles in clinical and basic science from around the world [1]." In deference to Imamura's will, Nobutoshi Ando, Editor Emeritus, who was the first Editor-in-Chief of the journal, made a great effort to establish everything that was necessary for publishing issues of the new journal from 2003 to 2011 . Since then, the quality has gradually improved. Soji Ozawa has been serving as the second Editor-in-Chief since 2012.

The first objective of the Editorial Committee was to determine the impact factor (IF), which is one of the quantitative tools that is used as a measure of the frequency with which the "average article" in a journal is cited in a particular year or period. The IF is useful for clarifying the significance of absolute citation frequencies [2]. The initial IF was 0.659 in 2011, 0.833 in 2012 and 0.741 in 2013. However, it decreased to 0.325 in 2014 and to 0.386 in 2015. The Editorial Committee had to consider an intensive plan to improve the IF.

The IF is calculated by dividing the number of current year citations with the source items published in that journal during the previous 2 years. The Editorial Committee asked chairpersons to recommend high-quality papers presented in the 69th Annual Meeting of the Japan Esophageal Society in 2015 as possible submissions to Esophagus to increase the number of submissions. This recommendation system continues until today. The total number of submissions has been increasing since, as follows: 105 in 2015, 122 in 2016, 81 in 2017, 148 in 2018, and 181 in 2019. In addition to

Soji Ozawa

sozawa@ tokai.ac.jp

1 Department of Gastroenterological Surgery, Tokai University School of Medicine, Kanagawa, Japan original articles, special articles were actively published in the journal, such as the Japanese Classification of Esophageal Cancer, 11th Edition, Esophageal Cancer Practice Guidelines 2017, Comprehensive Registry of Esophageal Cancer in Japan, Prediction of the Invasion Depth of Superficial Squamous Cell Carcinoma Based on Microvessel Morphology: Magnifying Endoscopic Classification of the Japan Esophageal Society, Newly Developed Magnifying Endoscopic Classification of the Japan Esophageal Society to Identify Superficial Barrett's Esophagus-Related Neoplasms, and Descriptive Rules for Achalasia of the Esophagus, 4th Edition.

MEDLINE is the premier U.S. National Library of Medicine bibliographic database that contains more than 25 million references to journal articles in the life sciences, with a concentration of articles on biomedicine [3]. In 2018, the Director of the National Library of Medicine decided to index Esophagus in MEDLINE, based on considerations of both scientific policy and scientific quality. PubMed, of which MEDLINE is the primary component, is a free resource supporting the search and retrieval of peerreviewed biomedical and life sciences literature, with the aim of improving health, both at the individual level and at the global level [4]. Therefore, researchers have been able to search articles in Esophagus using PubMed, and more and more articles published in Esophagus have been cited. Also, Esophagus has received a higher number of manuscripts since 2018. Consequently, the IF has increased as follows: 0.773 in 2016, 0.991 in 2017, and 2.061 in 2018, because of multiple favorable factors.

As for contributions by country, Japan contributed $85 \%$ of the articles in 2016 and 2018. More contributions from other countries are needed for Esophagus to become more internationally recognized. Fortunately, Esophagus has been indexed to MEDLINE, has an IF of 2.061, and is now well-known as a special journal which is indispensable to researchers on esophagology. We can expect more contributions from around the world hereafter. We truly appreciate everyone's contribution to Esophagus. It is our sincere hope that Esophagus will become a journal where the fruits 
of researchers' efforts will be published, so that as many patients with diseases of the esophagus and related organs as possible can receive better treatment.

\section{Funding None.}

\section{Compliance with ethical standards}

Ethical Statement This article does not contain any studies with human or animal subjects performed by the any of the author.

Conflict of interest The author declares that he has no conflict of interest.

\section{References}

1. Imamura M. Foreword from the chief of the journal organizing committee of esophagus. Esophagus. 2003;1:1.

2. The Clarivate Analytics Impact Factor, Clarivate Analytics. https://clarivate.com/webofsciencegroup/essays/impact-factor/. Accessed 31 Dec 2019.

3. MEDLINE® Journal Selection, U.S. National Library of Medicine. https://www.nlm.nih.gov/lstrc/jsel.html. Accessed 31 Dec 2019.

4. PubMed Overview, U.S. National Library of Medicine. https:// www.nlm.nih.gov/bsd/pubmed.html. Accessed 31 Dec 2019.

Publisher's Note Springer Nature remains neutral with regard to jurisdictional claims in published maps and institutional affiliations. 